\title{
Inhaltsverzeichnis
}

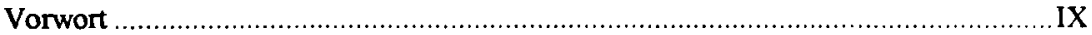

Verzeichnis der Abbildungen, Graphiken und Tabellen...................................... XIII

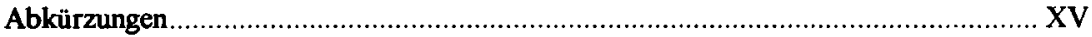

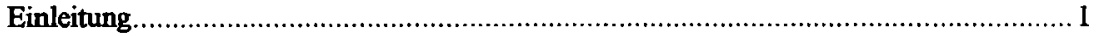

\section{Teil I: Forschungsüberblick}

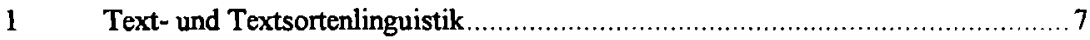

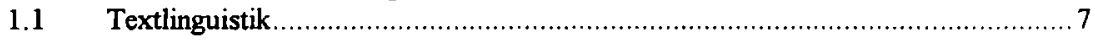

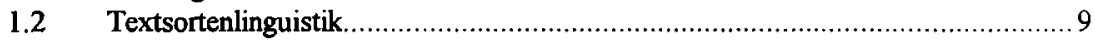

1.2.1 Der Begriff 'Textsorte' - Terminologie und Definition.................................. 10

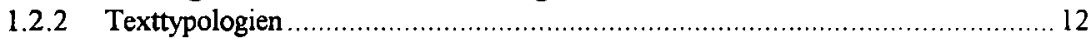

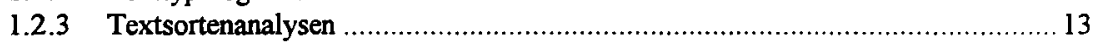

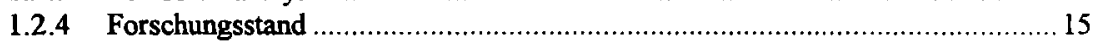

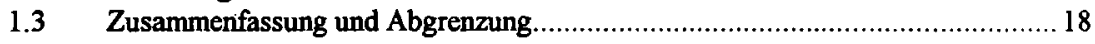

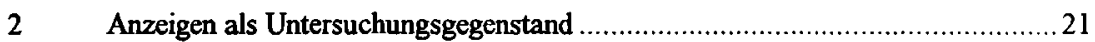

2.1 Zum Problem einer Anzeigentypologie .................................................. 21

2.2 Anzeigen in der sprachwissenschaftlichen Forschung ................................. 24

2.3 Untersuchungen $z u$ verschiedenen Anzeigenarten ..................................... 26

2.4 Untersuchungen zur Textsorte 'Todesanzeige' ......................................... 30

2.5 Zusammenfassung und Abgrenzung ......................................................... 35

\section{Teil II: Theoretische Grundlagen}

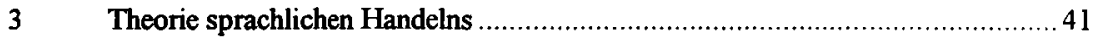

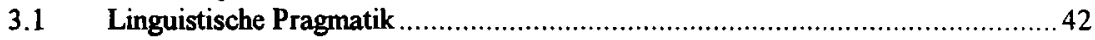

3.2 Sprachliches Handeln als Teil menschlichen Handelns ...............................4 43

3.3 Sprachliche Handlungen im Handlungsprozess (allgemeines Handlungsmodell) . . 46

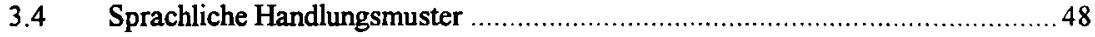

3.5 Sind Texte Handlungen? .............................................................................5 50

3.6 Die Ausweitung der Sprechakttheorie auf komplexe Äusserungsfolgen .............. 51

3.6.1 Grundzüge einer illokutiven Textanalyse..................................................... 52

3.6.2 Wie werden Illokutionen und ihre Verknüpfungen bestimmt?..........................5 54

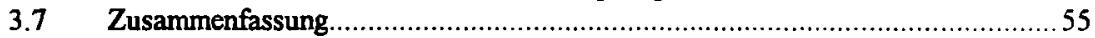

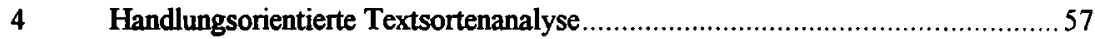

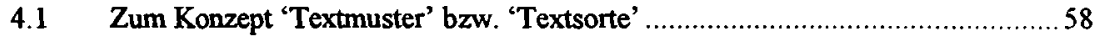

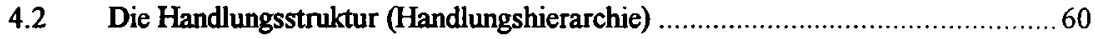

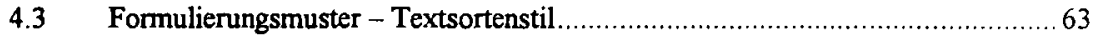

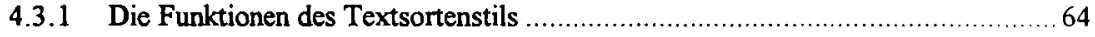

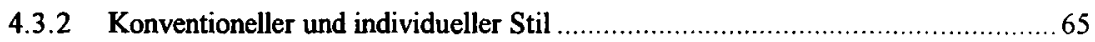

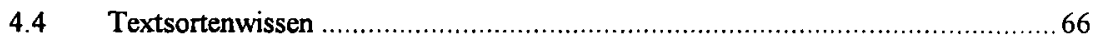

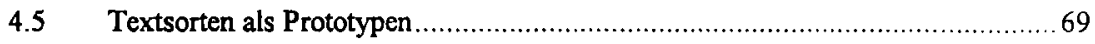




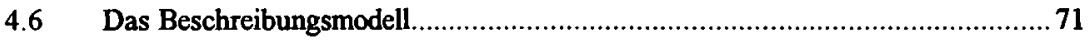

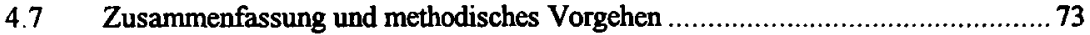

Teil III: Empirische Analyse der Textsorte 'Todesanzeige'

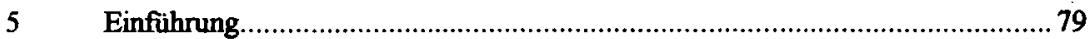

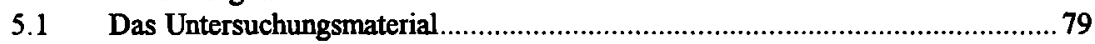

5.1.1 Auswahl der Zeitungen und Untersuchungszeitraum ........................................ 80

5.1.2 Umfang und Beschaffenheit des Anzeigenmaterials ......................................83

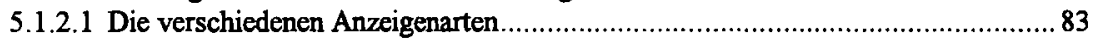

5.1.2.2 Die Unterscheidung von Familien- und Geschäftsanzeigen ............................ 84

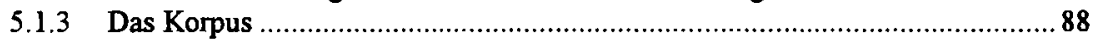

5.2 Die Textsorte ‘Todesanzeige' im Kontext der Zeitung ........................................ 90

5.2.1 Das Anzeigenwesen: zwei Systeme im Vergleich............................................... 90

5.2.2 Die Bedeutung der Todesanzeigen für die Zeitungen .................................. 92

5.2.3 Zeitungsspezifische Vorschriften und Richtlinien ........................................... 94

5.2.4 Die Bedeutung der Vorlagen bei der Abfassung der Todesanzeigen ......................97

5.2.5 Die Preise ................................................................................................. 99

5.3 Die Gesamthandlung ‘den Tod von XY bekanntgeben' - Die Beschreibung der einzelnen Stadien des Handlungsprozesses ................................................ 101

6 Die nonverbalen Eigenschaften - das äussere Erscheinungsbild der Textsorte

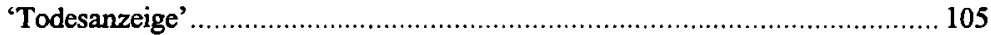

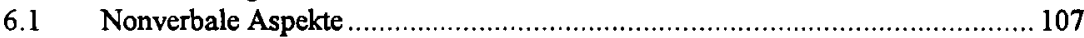

6.1.1 Plazierung in der Zeitung - Textumgebung............................................ 107

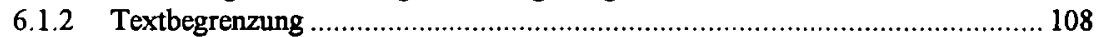

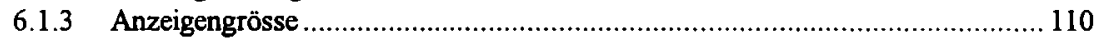

6.1.4 Spezielle nonverbale Zusätze - Symbole ................................................ 112

6.2 Paraverbale Aspekte (graphische Gestaltung) ........................................... 118

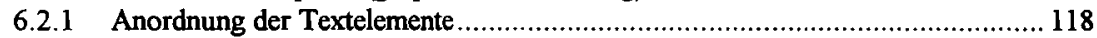

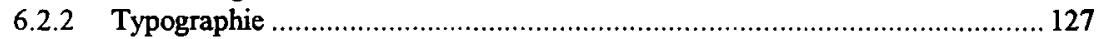

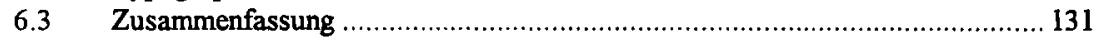

7 Handlungsstruktur I: Texthandlungen - Die Bestimmung der Textillokution

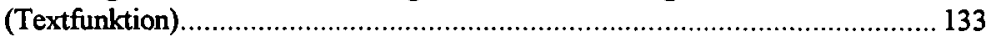

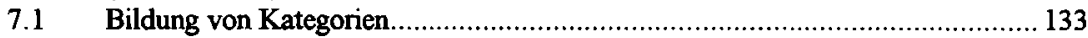

7.2 Die Texthandlungen - Bildung von Typen ......................................... 142

7.2.1 Die Bestimmung der Typen .................................................................... 149

7.2.2 Häufigkeit und Bedeutung der einzelnen Texthandlungen ............................... 164

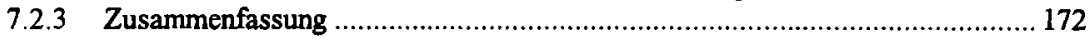

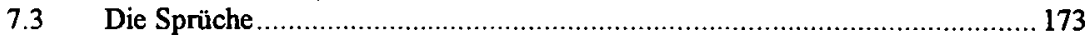

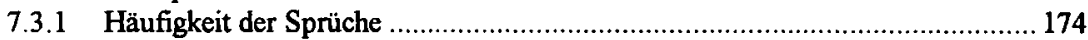

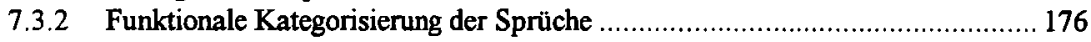

7.3.3 Quantitative und qualitative Analyse der Spruchkategorien ......................... 179

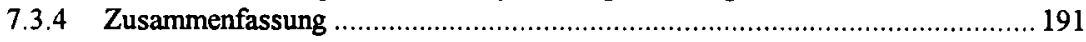

8 Handlungsstruktur II: Die Teil- und Zusatzhandlungen - Unterschiede innerhalb eines Typs ....................................................................................... 193

8.1 Die obligatorische Texthandlung 'Todesmitteilung' ................................... 193

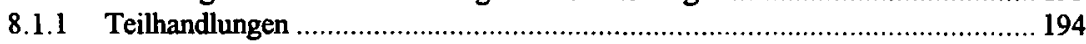




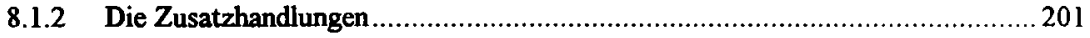

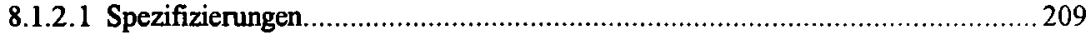

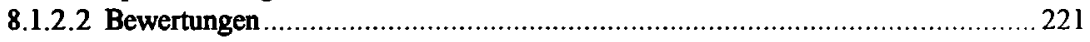

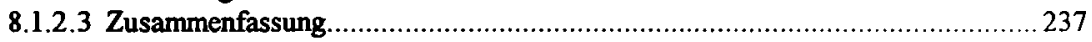

8.2 Die fakultativen und zusätzlichen Texthandlungen ............................... 238

8.2.1 Texthandlung 'Kontaktherstellung bzw. -verweigerung' ........................... 238

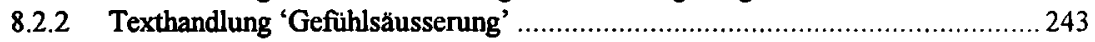

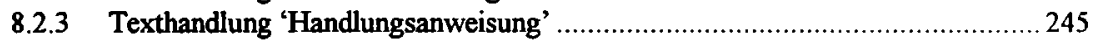

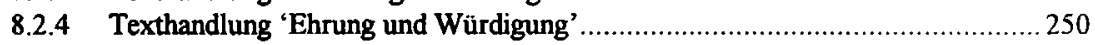

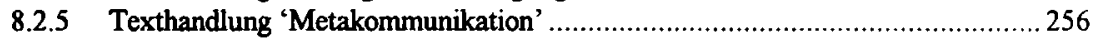

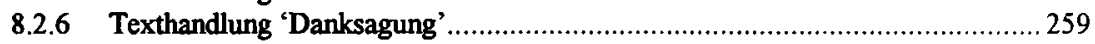

8.2.7 Texthandlung 'Ausdrücken von Wünschen und Hoffnungen'......................... 259

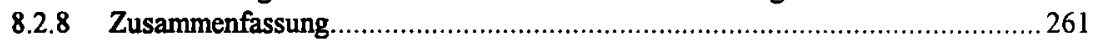

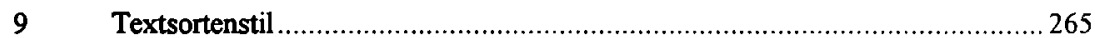

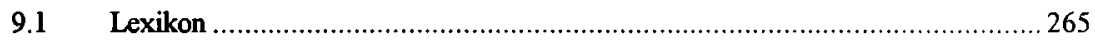

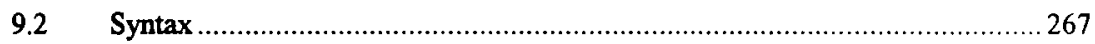

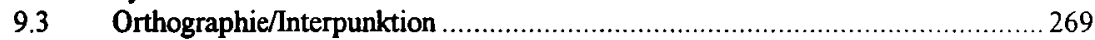

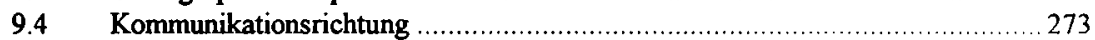

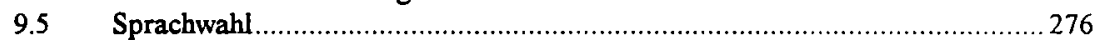

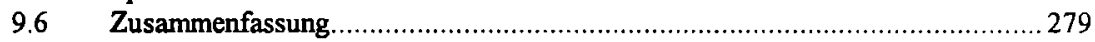

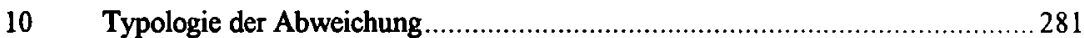

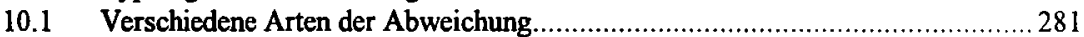

10.1.1 Abweichungen im Bereich der nonverbalen Eigenschaften ........................... 282

10.1.2 Verănderung der Textfunktion - Abweichungen im Bereich der verbalen

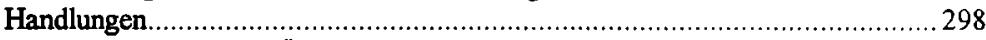

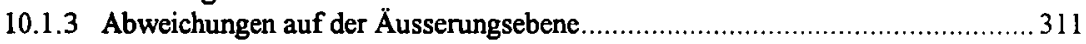

10.2 Strategien der Abweichung/Abweichungstypen .......................................... 315

10.2.1 Eine textsortentypische Handlung wird unkonventionell durchgeführt ............. 316

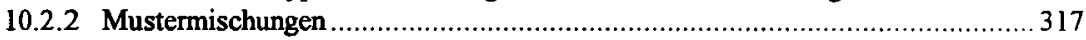

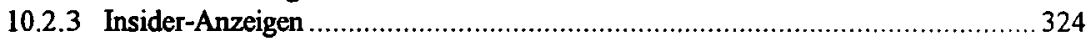

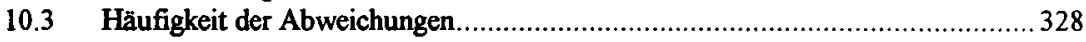

10.4 Zusammenfassung und Tendenzen ................................................... 330

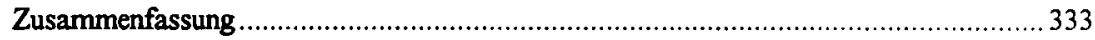

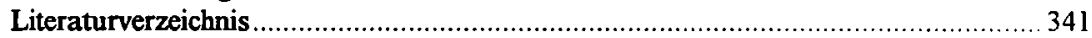

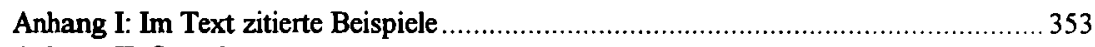

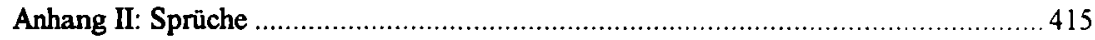

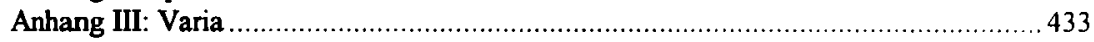


